\title{
A chromosomal method to distinguish between $X$ - and Y-bearing spermatozoa of the bull in zona-free hamster ova
}

\author{
H. Tateno and K. Mikamo \\ Department of Biological Sciences, Asahikawa Medical College, Asahikawa, Japan
}

\begin{abstract}
Summary. The interspecific in-vitro fertilization system using zona-free hamster ova was adopted to distinguish chromosomally between $\mathrm{X}$ - and $\mathrm{Y}$-bearing bull spermatozoa. Frozen semen samples were thawed and washed with modified BWW medium including $0.3 \%$ BSA ( $\mathrm{pH} 7 \cdot 2)$ to remove cryoprotective medium. Motile spermatozoa were recovered from the semen by the 'swim-up' method. These spermatozoa were treated with ionophore A23187 to facilitate capacitation. Adequate capacitation of spermatozoa was found by their movement patterns and the insemination was performed at the optimum time. The fertilized ova were cultured in Medium TC199 with $10 \%$ FBS including podophyllotoxin and vinblastine until they reached first cleavage metaphase. Chromosome slides were prepared by our gradual fixation-air drying method.

The success rate of the method was $56 \%$ of the number corresponding to the zonafree ova used. Altogether 1116 spermatozoa from 4 different bulls were successfully analysed and the ratio of $\mathrm{X}$ - and $\mathrm{Y}$-bearing spermatozoa was 542:574 $(P>0 \cdot 3)$.
\end{abstract}

\section{Introduction}

Direct analysis of sperm chromosomes of domestic animals has long been of interest, especially in the livestock industry. Such a method will certainly facilitate development of the technique for separating $\mathrm{X}$ - and Y-bearing spermatozoa which will make it possible to control the sex of offspring.

Direct chromosomal analysis has been possible for human spermatozoa by using the interspecific in-vitro fertilization system between zona-free hamster ova and artificially capacitated human spermatozoa (Rudak et al., 1978; Martin et al., 1982; Brandriff et al., 1984; Kamiguchi \& Mikamo, 1986). Zona-free hamster ova have also been shown to allow penetration of capacitated spermatozoa of many other mammalian species including the bull (Yanagimachi, 1984). To establish a practical method for chromosomally identifying the $\mathrm{X}$ - and $\mathrm{Y}$-bearing spermatozoa of the bull, we adopted the same zona-free hamster ova system and added several important modifications to our own method which has recently been shown to yield excellent results for human sperm chromosome analysis (Kamiguchi \& Mikamo, 1986).

In this report, we describe the procedures of our chromosomal technique for bull spermatozoa and some results thereby obtained.

\section{Materials and Methods}

Media. A modified BWW medium (mBWW; Table 1) supplemented with $0.3 \%$ bovine serum albumin (BSA) (fraction V, lot 84F-0099, No. A-8022, Sigma, St Louis, MO, U.S.A.) was used at pH 7.2 for handling bull spermatozoa and hamster eggs. The composition of Medium mBWW was the same as that of Medium BWW (Biggers et al., 1972) except that $\mathrm{NaCl}$ was increased to $5953.8 \mathrm{mg} / \mathrm{l}$ and $\mathrm{NaHCO}_{3}$ was reduced to $1500 \mathrm{mg} / \mathrm{l}$. Medium mBWW supplemented with BSA was used to make $0 \cdot 1 \%$ hyaluronidase (300 NF units $/ \mathrm{ml}$; Sigma) and $0 \cdot 1 \%$ trypsin $(1: 250 ;$ Difco, Detroit, MI, U.S.A.). To accelerate the capacitation of spermatozoa, ionophore A23187 (Calbiochem-Behring Corp., 
La Jolla, CA, U.S.A.) was used. It was dissolved in dimethyl sulphoxide (DMSO) at a concentration of $1 \mathrm{mM}$ and kept as the stock solution at $-20^{\circ} \mathrm{C}$. Immediately before use, the solution was diluted to $100 \mu \mathrm{M}$ with the BSA-supplemented Medium mBWW.

Medium mBWW containing a higher concentration of BSA (3.5\%) was prepared and adjusted to pH $7 \cdot 2$ for use in the final step of capacitation. The special capacitation medium was also used as the insemination medium. Medium TC199 (Nakarai Chemicals, Kyoto, Japan) supplemented with $28 \mathrm{mg}$ sodium pyruvate/1, $3 \cdot 7 \mathrm{ml}$ sodium lactate (60\% syrup) $/ 1$ and $10 \%$ heat-inactivated fetal bovine serum (FBS) (Gibco, New York, NY, U.S.A.) was used for culturing fertilized eggs.

Table 1. Composition of Medium mBWW

\begin{tabular}{lc}
\hline \multicolumn{1}{c}{ Component } & $\mathrm{mg} / 100 \mathrm{ml}$ \\
\hline $\mathrm{NaCl}$ & $595 \cdot 38$ \\
$\mathrm{KCl}$ & $35 \cdot 6$ \\
$\mathrm{CaCl}$ & $18 \cdot 9$ \\
$\mathrm{KH}_{2} \mathrm{PO}_{4}$ & $16 \cdot 2$ \\
$\mathrm{MgSO}_{4} \cdot 7 \mathrm{H}_{2} \mathrm{O}$ & $29 \cdot 4$ \\
$\mathrm{NaHCO}_{3}$ & $150 \cdot 0$ \\
$\mathrm{Glucose}_{\text {Sodium pyruvate }}$ & $100 \cdot 0$ \\
Sodium lactate & $2 \cdot 8$ \\
Potassium penicillin $\mathrm{G}$ & $0 \cdot 37 \mathrm{ml}(60 \%$ syrup $)$ \\
Streptomycin & $5 \cdot 6$ \\
Bovine serum albumin & $2 \cdot 5$ \\
$0 \cdot 2 \%$ phenol red & $300 \cdot 0$ \\
\hline
\end{tabular}

Preparation of zona-free eggs. Mature golden hamsters (Mesocricetus auratus) 6-12 weeks old were induced to superovulate by an intramuscular injection of $0 \cdot 2$ i.u. PMSG (Teikoku-Zoki Pharmaceuticals, Tokyo, Japan)/g body weight into the inguinal region on Day 1 (the day of ovulation) of the oestrous cycle and followed $58 \mathrm{~h}$ later by further administration of $0 \cdot 2$ i.u. hCG (Mochida Pharmaceuticals, Tokyo, Japan)/g body weight. Superovulated eggs ( $50-60$ eggs/animal) were collected from the ampullar region of the oviducts $17 \mathrm{~h}$ after the hCG injection and freed from cumulus cells by $0.1 \%$ hyaluronidase. Cumulus-free eggs were washed once in fresh Medium mBWW containing $0.3 \%$ BSA and treated with $0.1 \%$ trypsin to remove the zona pellucida. As soon as the zona pellucida was removed, the denuded eggs were washed twice in fresh Medium mBWW containing 0.3\% BSA and inseminated.

Preparation of bull spermatozoa. Semen samples from Holstein bulls were provided by the Livestock Improvement Association of Japan (Maebashi, Japan). The samples had been diluted approximately 15-fold with cryoprotective medium (about $1 \times 10^{8}$ spermatozoa $/ \mathrm{ml}$ and stored in liquid nitrogen $\left(-196^{\circ} \mathrm{C}\right)$.

Immediately before use, one or two straws $\left(0.5 \mathrm{ml}\right.$ each) were thawed quickly in a water bath at $37^{\circ} \mathrm{C}$. The thawed semen sample was diluted approximately 3 -fold with Medium $\mathrm{mBWW}$ containing $0 \cdot 3 \%$ BSA and centrifuged at $550 \mathrm{~g}$ for $5 \mathrm{~min}$ to remove the cryoprotective medium. After the pellet of spermatozoa was resuspended in $0.5 \mathrm{ml} \mathrm{Medium}$ $\mathrm{mBWW}$ containing $0.3 \%$ BSA, the suspension was divided into 2 or 3 test tubes containing $2 \mathrm{ml}$ of the same medium. These test tubes were kept still at $37^{\circ} \mathrm{C}$ in a humidified incubator with a gas phase $5 \% \mathrm{CO}_{2}$ and $95 \%$ air for $1 \mathrm{~h}$ to allow motile spermatozoa to swim upwards. The suspension of active spermatozoa was centrifuged and the pellet was resuspended in fresh Medium mBWW containing $0.3 \%$ BSA.

The sperm suspension was halved and each was treated separately with 10 or $15 \mu \mathrm{M}$ ionophore for $10 \mathrm{~min}$ in the incubator to facilitate the capacitation. These suspensions were centrifuged and washed once with Medium mBWW containing $0.3 \%$ BSA to remove ionophore. They were then put together to mix spermatozoa which were treated with different concentrations of ionophore. This procedure was necessary because there were individual variations in response to ionophore between different sperm samples, and adequate ionophore treatment for each sample was not predictable. The spermatozoa were resuspended in a droplet $(0.15 \mathrm{ml})$ of the capacitation medium (Medium mBWW containing $3.5 \%$ BSA) at a concentration of $1 \times 10^{4}-10^{5}$ spermatozoa $/ \mathrm{ml}$. This droplet had been placed in a sterile plastic Petri dish $(35 \times 12 \mathrm{~mm})$ and covered with paraffin oil (Art. 7162, Merck, Darmstadt, FRG). The suspension was kept in the incubator for $3-3.5 \mathrm{~h}$ to permit capacitation.

Confirmation of the capacitation of spermatozoa. It was possible to determine whether bull spermatozoa were adequately capacitated by watching their movement patterns under an inverted microscope at magnification of $\times 100$. For very accurate behavioural analysis, however, we recorded the movement of spermatozoa in Microscopic High Speed Video (NAC Inc., Tokyo, Japan) (Fig. 1). The spermatozoa moved progressively after the thawing. When the 


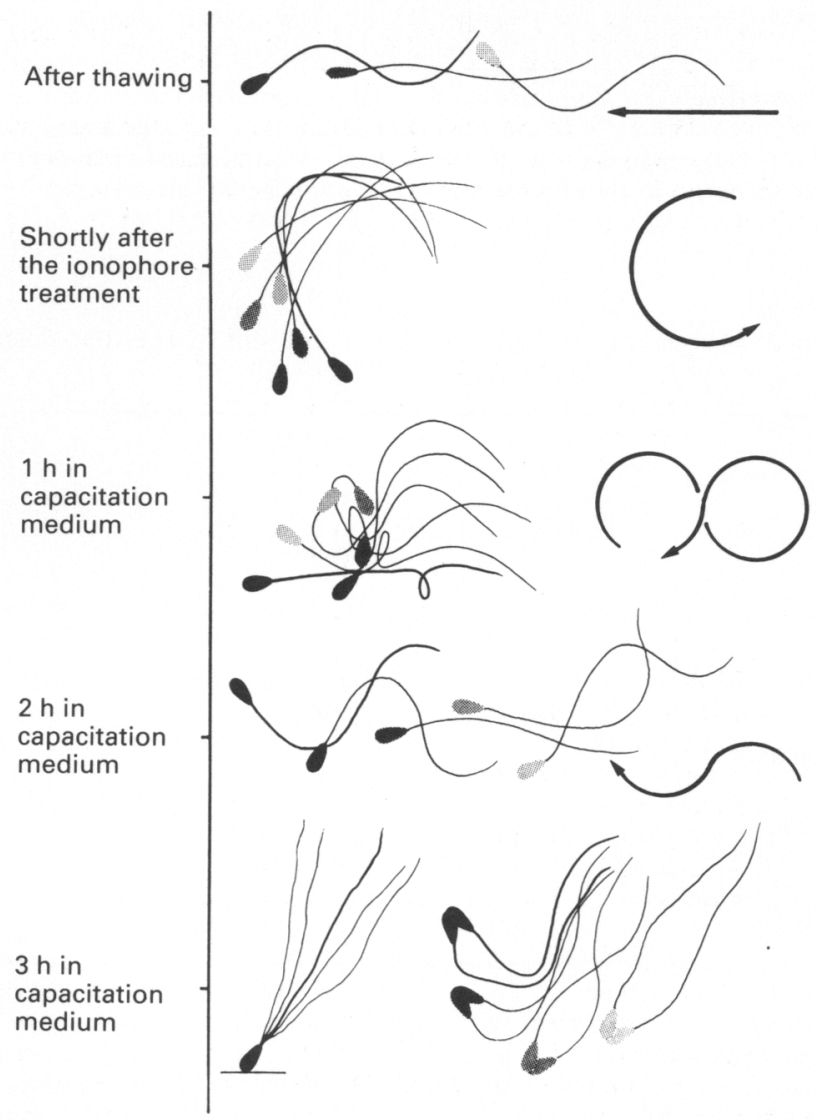

Fig. 1. Changing aspects of movement patterns of bull spermatozoa during in-vitro capacitation. Their movement is shown by tracks of the head, from the light position to the dark position, and by the shapes of typical flagellar beats of the tail. The arrows indicate direction of locomotion.

ionophore treatment had finished and the spermatozoa had been transferred to the capacitation medium for incubation, they stopped progressive movement and started to circle around themselves by beating the entire length of the tails. This action was seen to be quite stiff. From $30 \mathrm{~min}$ to $1 \mathrm{~h}$ after incubation, a considerable number of spermatozoa showed vigorous movement of the neck and the tail, i.e. 'hyperactive movement' (Yanagimachi, 1981). About $1 \mathrm{~h}$ later, the majority of spermatozoa began to move progressively by a flexible beating of the tail. At the end of the incubation period (3-3.5 h), the head of the spermatozoon became sticky. Consequently, some spermatozoa started to attach to the bottom of the dish and vibrated their tails, while 2 or 3 spermatozoa stuck to each other in a head-tohead association and wandered about. At this moment, we judged that the spermatozoa were adequately capacitated.

Insemination and culture. Zona-free eggs from 2-6 animals, about 100-300 eggs, were put all together into the capacitated sperm suspension and left for 10-20 min. When 20-30 spermatozoa had attached to the surface of each egg, the eggs were transferred to a sperm-free capacitation medium to avoid extreme polyspermic fertilization. About 15 min later, they were washed twice in the culture medium (Medium TC199 with 10\% FBS) to remove excessive spermatozoa. Then they were transferred to the culture medium under paraffin oil in a plastic Petri dish and cultured in the incubator.

Arrest of karyogamy and formation of the 1st cleavage spindle. After $8 \mathrm{~h}$, podophyllotoxin (Sigma) and vinblastine (Sigma) were added to the medium at a final concentration of $0.06 \mu \mathrm{g} / \mathrm{ml}$ for both chemicals. The former was to interrupt karyogamy and the latter to block the tubulin polymerization necessary for spindle formation; these substances were effective in comparison with colchicine and Colcemid, as described by Kamiguchi \& Mikamo (1986). At $10 \mathrm{~h}$ after the addition of the chemicals ( $18 \mathrm{~h}$ after the insemination), metaphasic eggs having no visible pronuclei in 
the cytoplasm were selected and cultured for a further $2 \mathrm{~h}$ to allow chromosomes to condense adequately. The remaining eggs were also treated in the same way as soon as they reached metaphase.

Preparation of chromosome slides. Our gradual fixation-air drying method (Mikamo \& Kamiguchi, 1983) was used for preparing chromosome slides. This method was originally designed for oocytes and early zygotes of the Chinese hamster. The method was slightly modified for golden hamster eggs (Kamiguchi \& Mikamo, 1986). Routinely, chromosome slides were stained with 25 -fold diluted Giemsa solution for $30 \mathrm{~min}$.

Table 2. Technical data of sex chromosome analysis of bull spermatozoa using zona-free golden hamster oocytes

\begin{tabular}{|c|c|c|c|c|c|}
\hline & \multicolumn{4}{|c|}{ Bull } & \multirow[b]{2}{*}{ Total } \\
\hline & A & B & $\mathrm{C}$ & D & \\
\hline No. of experiments & 1 & 1 & 1 & 1 & 4 \\
\hline No. of oocytes used & $\begin{array}{l}101 \\
(100 \cdot 0)\end{array}$ & $\begin{array}{l}284 \\
(100 \cdot 0)\end{array}$ & $\begin{array}{l}172 \\
(100 \cdot 0)\end{array}$ & $\begin{array}{l}175 \\
(100 \cdot 0)\end{array}$ & $\begin{array}{l}732 \\
(100 \cdot 0)\end{array}$ \\
\hline $\begin{array}{l}\text { No. of oocytes penetrated } \\
(\%)\end{array}$ & $\begin{array}{l}93 \\
(92 \cdot 1)\end{array}$ & $\begin{array}{l}230 \\
(81 \cdot 0)\end{array}$ & $\begin{array}{l}143 \\
(83 \cdot 1)\end{array}$ & $\begin{array}{l}127 \\
(72 \cdot 6)\end{array}$ & $\begin{array}{l}593 \\
(81 \cdot 0)\end{array}$ \\
\hline $\begin{array}{l}\text { No. of metaphasic eggs } \\
(\%)\end{array}$ & $\begin{array}{l}66 \\
(65 \cdot 3)\end{array}$ & $\begin{array}{l}151 \\
(53 \cdot 2)\end{array}$ & $\begin{array}{l}116 \\
(67 \cdot 4)\end{array}$ & $\begin{array}{l}106 \\
(60 \cdot 6)\end{array}$ & $\begin{array}{l}439 \\
(60 \cdot 0)\end{array}$ \\
\hline $\begin{array}{l}\text { No. of analysable eggs } \\
(\%)\end{array}$ & $\begin{array}{l}54 \\
(53 \cdot 5)\end{array}$ & $\begin{array}{l}106 \\
(37 \cdot 3)\end{array}$ & $\begin{array}{l}67 \\
(40 \cdot 0)\end{array}$ & $\begin{array}{l}77 \\
(44 \cdot 0)\end{array}$ & $\begin{array}{l}304 \\
(41 \cdot 5)\end{array}$ \\
\hline $\begin{array}{l}\text { No. of spermatozoa identified* } \\
(\%) \dagger\end{array}$ & $\begin{array}{c}82 \\
(81 \cdot 2)\end{array}$ & $\begin{array}{l}125 \\
(44 \cdot 0)\end{array}$ & $\begin{array}{l}86 \\
(50 \cdot 0)\end{array}$ & $\begin{array}{l}114 \\
(65 \cdot 1)\end{array}$ & $\begin{array}{l}407 \\
(55 \cdot 6)\end{array}$ \\
\hline
\end{tabular}

*This was greater than the number of analysable eggs in every experiment, because a considerable number of eggs had more than two male pronuclei due to polyspermy and they were chromosomally analysable.

$\dagger$ Success rate is represented by $\frac{\text { the no. of spermatozoa identified }}{\text { the no. of oocytes used }} \times 100$.

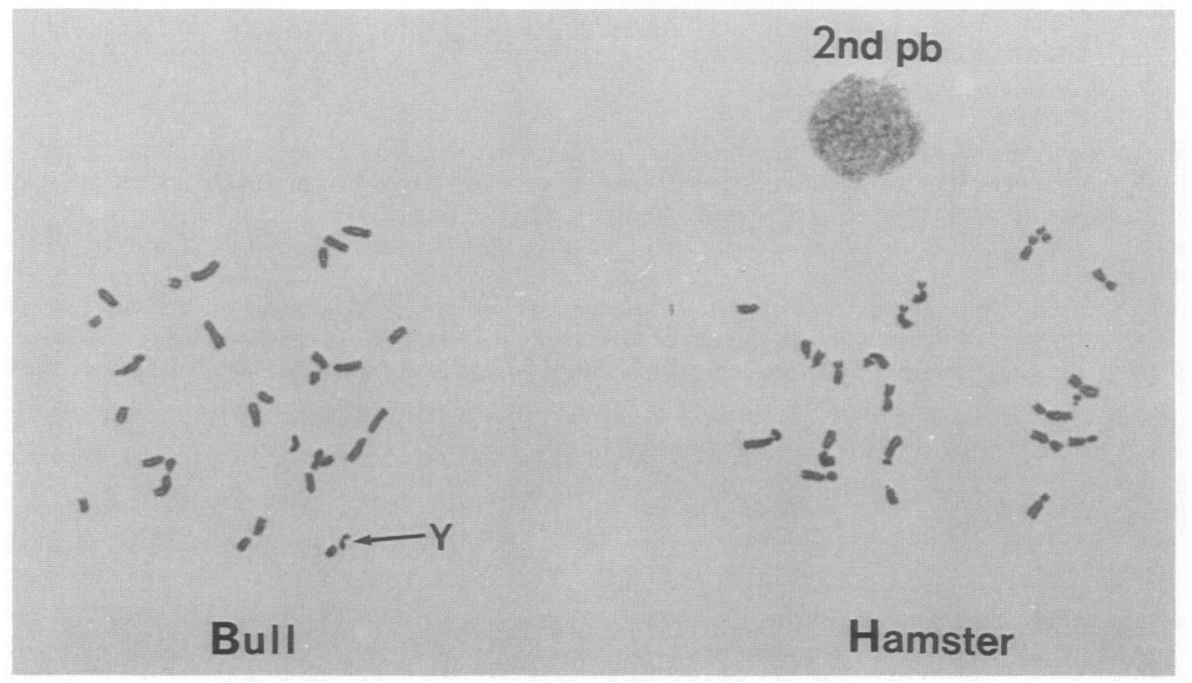

Fig. 2. A chromosome preparation of a hamster egg penetrated by a $\mathrm{Y}$-bearing spermatozoon of the bull. The second polar body can be seen. $\times 420$. 


\section{Results}

Using semen samples from 4 bulls, one experiment for each bull was carried out. To determine the precise rate of penetration and the success rate of chromosome analysis, all eggs used for insemination were processed up to the final steps for chromosome slide preparation (Table 2). Among them, $72 \cdot 6-92 \cdot 1 \%$ were found to be penetrated by bull spermatozoa. In some of them, the development was arrested at the swollen sperm head stage or early pronuclear stage, but the remaining ones $(53 \cdot 2-67 \cdot 4 \%)$ reached the first cleavage metaphase (Fig. 2). In many of these metaphasic eggs $\mathrm{X}$ - and $\mathrm{Y}$-bearing spermatozoa were identified easily because the sex chromosomes of the bull are morphologically very different from each other and also from all autosomes (Fig. 3). Finally, $37 \cdot 3-53.5 \%$ (mean $41.5 \%$ ) of the eggs used were analysed. Eggs with two or more analysable male chromosome plates were often obtained and so the number of spermatozoa analysed was considerably higher than that of analysable eggs. Therefore, the final rates of success (the number of spermatozoa identified/the number of oocytes used $\times 100$ ) increased to $44 \cdot 0-81 \cdot 2 \%$ (mean 55.6\%) (Table 2).
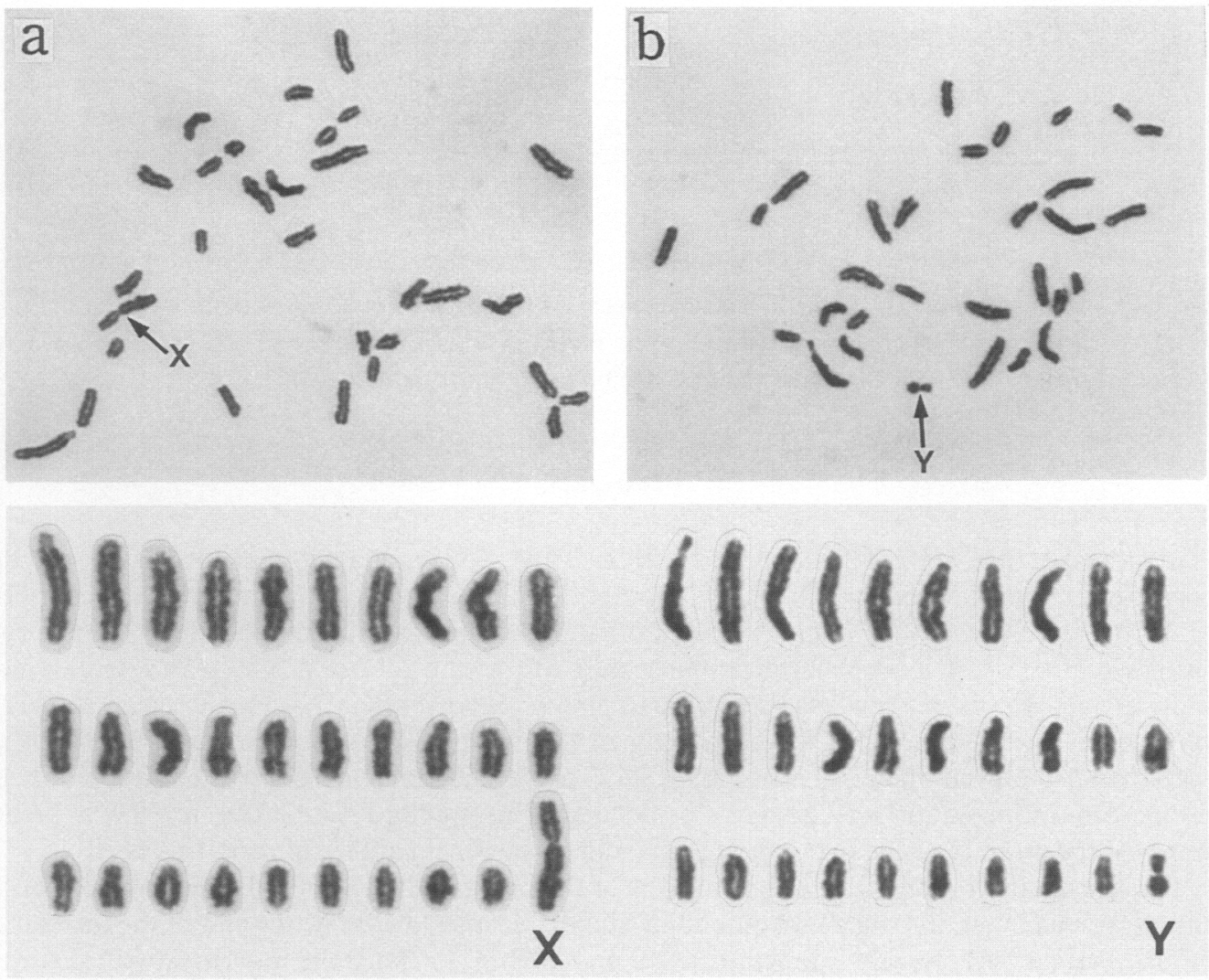

Fig. 3. A metaphase plate of an X-bearing (a) and a Y-bearing (b) spermatozoon. Autosomes are all acro- or telocentric, while the $\mathrm{X}$ is a large submetacentric and the $\mathrm{Y}$ is a small submetacentric. Chromosome plates, $\times 550$; karyotypes, $\times 900$. 
Table 3. Results of sex chromosome analysis in post-thaw bull sperm samples

\begin{tabular}{|c|c|c|c|c|c|}
\hline Bull & Exp. & $\begin{array}{l}\text { No. of } \\
\text { spermatozoa } \\
\text { analysed }\end{array}$ & $\begin{array}{c}\text { X-bearing } \\
\text { spermatozoa } \\
(\%)\end{array}$ & $\begin{array}{c}\text { Y-bearing } \\
\text { spermatozoa } \\
(\%)\end{array}$ & $\begin{array}{c}\text { Difference from } \\
\text { the } 1: 1 \text { ratio } \\
\left(\chi^{2} \text { test }\right)\end{array}$ \\
\hline \multirow[t]{7}{*}{ A } & 1 & 82 & $44(53 \cdot 7)$ & $38(46 \cdot 3)$ & $P>0.5$ \\
\hline & 2 & 78 & $37(47 \cdot 4)$ & $41(52 \cdot 6)$ & $P>0.7$ \\
\hline & 3 & 105 & $50(47 \cdot 6)$ & $55(52 \cdot 4)$ & $P>0.7$ \\
\hline & 4 & 48 & $24(50 \cdot 0)$ & $24(50.0)$ & $P=1 \cdot 0$ \\
\hline & 5 & 70 & $39(55 \cdot 7)$ & $31(44 \cdot 3)$ & $P>0.3$ \\
\hline & 6 & 76 & $42(55 \cdot 3)$ & $34(44 \cdot 7)$ & $P>0.5$ \\
\hline & 6 & 459 & $236(51 \cdot 4)$ & $223(48 \cdot 6)$ & $P>0.5$ \\
\hline \multirow[t]{3}{*}{ B } & 1 & 125 & $58(46 \cdot 4)$ & $67(53 \cdot 6)$ & $P>0.5$ \\
\hline & 2 & 109 & $48(44 \cdot 0)$ & $61(56 \cdot 0)$ & $P>0.3$ \\
\hline & 2 & 234 & $106(45 \cdot 3)$ & $128(54 \cdot 7)$ & $P>0.2$ \\
\hline \multirow[t]{4}{*}{$\mathrm{C}$} & 1 & 86 & $44(51 \cdot 2)$ & $42(48 \cdot 8)$ & $P>0.8$ \\
\hline & 2 & 50 & $24(48 \cdot 0)$ & $26(52 \cdot 0)$ & $P>0.8$ \\
\hline & 3 & 62 & $32(51 \cdot 6)$ & $30(48 \cdot 4)$ & $P>0.8$ \\
\hline & 3 & 198 & $100(50 \cdot 5)$ & $98(49 \cdot 5)$ & $P>0.9$ \\
\hline \multirow[t]{4}{*}{ D } & 1 & 114 & $48(42 \cdot 1)$ & $66(57.9)$ & $P>0.2$ \\
\hline & 2 & 59 & $25(42 \cdot 4)$ & $34(57.6)$ & $P>0.3$ \\
\hline & 3 & 52 & $27(51 \cdot 9)$ & $25(48 \cdot 1)$ & $P>0.8$ \\
\hline & 3 & 225 & $100(44 \cdot 4)$ & $125(55 \cdot 6)$ & $P>0.2$ \\
\hline Total & 14 & 1116 & $542(48 \cdot 6)$ & $574(51 \cdot 4)$ & $P>0.3$ \\
\hline
\end{tabular}

To examine the ratio of $\mathrm{X}$ - to $\mathrm{Y}$-bearing spermatozoa in semen samples from 4 different bulls, the experiments were repeated according to the method described above (Table 3 ). There was no significant difference from the expected one to one ratio in any of the experiments $\left(\chi^{2}\right.$ test).

\section{Discussion}

As described earlier, the composition of Medium BWW was modified to make it suitable for bull spermatozoa and hamster eggs. Ordinary Medium BWW was devised to maintain a constant $\mathrm{pH}$ of $7 \cdot 3-7.4$ under $5 \% \mathrm{CO}_{2}-95 \%$ air by a bicarbonate- $\mathrm{CO}_{2}$ buffer system. Therefore, its $\mathrm{pH}$ rises during the process of in-vitro fertilization in pure air, owing to loss of $\mathrm{CO}_{2}$. The development ability of zona-free hamster ova is vulnerable to $\mathrm{pH}$ values higher than $7 \cdot 4$. Furthermore, the $\mathrm{pH}$ of bull semen is known to be $6 \cdot 6-6 \cdot 8$. Accordingly, in Medium mBWW the concentration of $\mathrm{NaHCO}_{3}$ was reduced to prevent the $\mathrm{pH}$ from exceeding $7 \cdot 2$, and at the same time the concentration of $\mathrm{NaCl}$ was increased to maintain an acceptable osmolarity. This modification of Medium BWW greatly improved the motility of the bull spermatozoa and development ability of zona-free eggs.

It was useful to watch the changing aspects of the motion patterns of bull spermatozoa for the purpose of understanding their corresponding stages of capacitation. At the end of the incubation period, spermatozoa showed characteristic behaviour (Fig. 1). Since the movement patterns were used as an indicator to confirm adequate capacitation, the insemination could be performed at the optimum time and the success of the in-vitro fertilization was assured in every experiment.

It has been reported that sperm capacitation ability was very different amongst bull semen samples (Iritani et al., 1986). In our system, however, we were able to minimize this individual 
variation, and to raise the rate of sperm capacitation, by treating the spermatozoa with two different concentrations of ionophore.

We increased the concentration of vinblastine and podophyllotoxin and lengthened the time for allowing the condensation of chromosomes, as compared with the method for human sperm chromosomes. In the slides which were made before these modifications were applied, chromosomes were often twisted and overlapped because of inadequate condensation of chromatin. These modifications were therefore important in yielding the excellent results in the chromosome analysis.

We have no information on the sex ratio in the offspring of the bulls from which the semen samples were used in this experiment. It has been said that the sex ratio in newborn calves is usually between 51 and $53 \%$, suggesting that the primary sex ratio must be very close to $1: 1$ (Johansson et al., 1974; Powell et al., 1975; Foote, 1977; Skjervold \& James, 1979; King et al., 1985). In our experiments, the sex ratios obtained for each experiment, as well as for each bull, showed that there was no statistical difference from the 1:1 ratio. Our results suggest that there was no selection of either $\mathrm{X}$ - or $\mathrm{Y}$-bearing spermatozoa during the process of our interspecific in-vitro fertilization system using zona-free hamster ova.

At the present time, artificial insemination (AI) is popular in the breeding of cattle, and quality of semen samples is routinely evaluated by morphological and physiological examinations. In addition to these, our present technique will be useful for cytogenetic screening of semen samples before permitting their extensive use in AI programmes. It is desirable to apply chromosomal banding methods in order to facilitate detection of structural chromosomal aberrations.

We thank Mr S. Nagoaka, the director, and Dr K. Hamano, the Technical Center of the Livestock Improvement Asso. of Japan, Inc., Maebashi, Japan, for providing us with frozen semen samples of bulls and their information useful for this study, and $\mathrm{Mr} \mathrm{M}$. N. Weedon-Newstead, the English instructor of our school, for checking the English of this manuscript.

\section{References}

Biggers, J.D., Whitten, W.K. \& Whittingham, D.G. (1972) The culture of mouse embryos in vitro. In Methods in Mammalian Embryology, pp. 86-116. Ed. J. C. Daniel, Jr. Freeman, San Francisco.

Brandriff, B., Gordon, L., Ashworth, L., Watchmarker, G., Carrano, A. \& Wyrobek, A. (1984) Chromosomal abnormalities in human sperm: Comparisons among four healthy men. Hum. Genet. 66, 193-201.

Foote, R.H. (1977) Sex ratios in dairy cattle under various conditions. Theriogenology 8, 349-356.

Iritani, A., Utsumi, K., Miyake, M. \& Yamaguchi, Y. (1986) Individual variation in the in vitro fertilizing ability of bull spermatozoa. Develop. Growth Diff. 28 (Suppl.), 45, Abstr.

Johansson, I., Lindhé, B. \& Pirchner, F. (1974) Causes of variation in the frequency of monozygous and dizygous twinning in various breeds of cattle. Hereditas 78, 201-234.

Kamiguchi, Y. \& Mikamo, K. (1986) An improved, efficient method for analyzing human sperm chromosomes using zona-free hamster ova. Am. J. hum. Genet. 38, 724-740.

King, K.K., Seidel, G.E., Jr \& Elsden, R.P. (1985) Bovine embryo transfer pregnancies. I. Abortion rates and characteristics of calves. J. Anim. Sci. 61, 747-757.

Martin, R.H., Lin, C.C., Balkan, W. \& Burns, K. (1982) Direct chromosomal analysis of human spermatozoa; preliminary results from 18 normal men. $\mathrm{Am}$. J. hum. Genet. 34, 459-468.
Mikamo, K. \& Kamiguchi, Y. (1983) A new assessment system for chromosomal mutagenicity using oocytes and early zygotes of the Chinese hamster. In Radiation-Induced Chromosome Damage in Man, pp. 411432. Eds T. Ishihara \& M. Sasaki. Alan R. Liss, New York.

Powell, R.L., Norman, H.D. \& Dickinson, F.N. (1975) Sire differences in sex ratio of progeny. J. Dairy Sci. 58, 1723-1726.

Rudak, E., Jacobs, P.A. \& Yanagimachi, R. (1978) Direct analysis of the chromosome constitution of human spermatozoa. Nature, Lond. 274, 911-913.

Skjervold, H. \& James, J.W. (1979) Causes of variation in the sex ratio in dairy cattle. Z. Tierzücht. ZuchtBiol. 95, 293-305.

Yanagimachi, R. (1981) Mechanisms of fertilization in mammals. In Fertilization and Embryonic Development In Vitro, pp. 81-182. Eds L. Mastroianni \& J. D. Biggers. Plenum Press, New York.

Yanagimachi, R. (1984) Zona-free hamster eggs: their use in assessing fertilizing capacity and examining chromosomes of human spermatozoa. Gamete Res. 10, 187-232. 